\author{
Wacław Szcześniak \\ Prof. dr hab. inż. \\ Wydział Inżynierii Lądowej, \\ Politechnika Warszawska \\ w.szczesniak@il.pw.edu.pl \\ Magdalena Ataman \\ Dr inż. \\ Wydział Inżynierii Lądowej, \\ Politechnika Warszawska \\ m.ataman@il.pw.edu.pl
}

DOI: 10.35117/A_ENG_19_11_05

\title{
Change of constraints in rope articulated structures
}

\begin{abstract}
In the paper four examples of two-dimensional and three-dimensional material systems, in which some of constraints were suddenly removed, are analyzed. A simple structure consisting of two ropes and a particle, a spatial structure consisting of three weightless ropes and a particle, and a beam suspended on two ropes and a circular shield, also suspended on two ropes, were analyzed. In all cases one of the ropes was suddenly cut. Solutions were obtained by the analytical method, using the properties of the instantaneous center of acceleration. The obtained results are illustrated by diagrams of accelerations, angular accelerations and forces acting in the considered systems.
\end{abstract}

Keywords: Articulated structures; Change of constraints;

\section{Introduction}

A sudden change in constraints in building structures often leads to emergency conditions and catastrophic engineering structures [3]. The subject of considerations in this paper is flat and spatial material systems. Four sample structures were solved, in which some of the constraints were suddenly removed. At the initial moment $t=0^{+}$, just after the change of constraints, accelerations were determined, as well as the arrangement of all external reactions and internal forces in unstretched ropes. The tasks were solved by an analytical method using the properties of the temporary acceleration centre [10-15]. It should be emphasized that at the moment $t=0^{+}$there are no velocities and angular velocities in the system yet, while there are accelerations as well as external and internal forces in the weakened material system. In such cases, the momentary centre of rotation (speed) coincides with the momentary centre of acceleration.

\section{A sudden change of constraints of the particle suspended on two and three ropes}

The flat structure shown in Figure 1, with material point $\mathrm{C}$ of weight $Q$ is considered. Initially (before removing the bonds), the forces in both ropes are equal. We determine them from the static equilibrium of node $\mathrm{C}$, we have an equation from which we determine the internal static forces equal in both bars:

$$
2 S_{\text {stat }} \cos \alpha=Q \rightarrow S_{\text {stat }}=\frac{Q}{2 \cos \alpha}
$$


Immediately after cutting the AC cable, the system does not have speed yet, but there is already an acceleration $a$ of the material point of weight $Q$. According to the designations in Figure 2, from the kinetostatic equations of node C, we find the force $S_{\mathrm{dyn}}$ in an uncut bar:

$$
\sum F_{y}=0 \rightarrow S_{\mathrm{dyn}} \cos \alpha+\frac{Q}{g} a \cos \left(\frac{\pi}{2}-\alpha\right)=Q \rightarrow S_{\mathrm{dyn}}=\frac{Q}{\cos \alpha}\left(1-\frac{a}{g} \sin \alpha\right) .
$$

We determine the acceleration $a$ using the kinetostatic equation of the sum of moments of all forces relative to point B (Fig. 2) of the horizontal ceiling at the moment $t=0^{+}$:

$$
\sum M_{\mathrm{B}}=0 \rightarrow Q l \sin \alpha-\frac{Q}{g} a l=0 \rightarrow a=g \sin \alpha .
$$

The ratio of dynamic force in $\mathrm{BC}$ cable to static force in this cable can be found as follows: $n=\frac{S_{\text {dyn }}}{S_{\text {stat }}}=2(\cos \alpha)^{2}$.

Graph of the function $n=n(\alpha)$, at $\alpha \in\left\langle 0, \frac{\pi}{2}\right\rangle$ is shown in picture 3 .

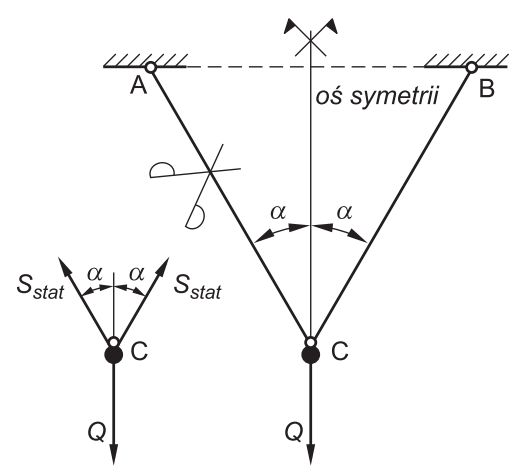

1. Static diagram of a flat structure before cutting the AC cable

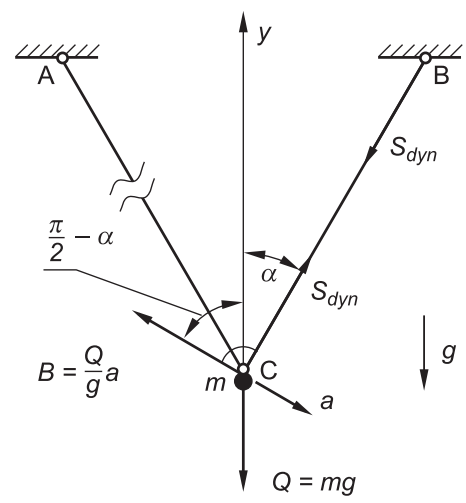

2. Dynamic diagram of a flat structure after cutting the AC cable 


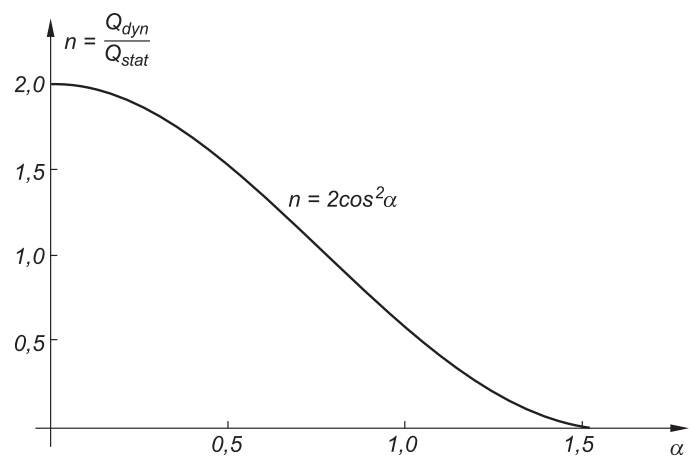

3. Graph of dynamic coefficient, function $n=n(\alpha)$, depending on the angle $\alpha \in\left\langle 0, \frac{\pi}{2}\right\rangle$

We will now consider a spatial structure consisting of three cables, hinged in a rigid horizontal ceiling at points $\mathrm{A}, \mathrm{B}$ and $\mathrm{C}$, and converging to point $\mathrm{S}$, where a particle with mass $m$ was suspended. The ropes have the same length $a$, while points $\mathrm{A}, \mathrm{B}$ and $\mathrm{C}$ are the vertices of an equilateral triangle with the given length of the side equal $2 b$, as in Figure 4 . The system remains in equilibrium in the Earth's gravitational field. At one point, the SB line was cut abruptly. We will determine the ratio of dynamic force to static force in each uncut cable.

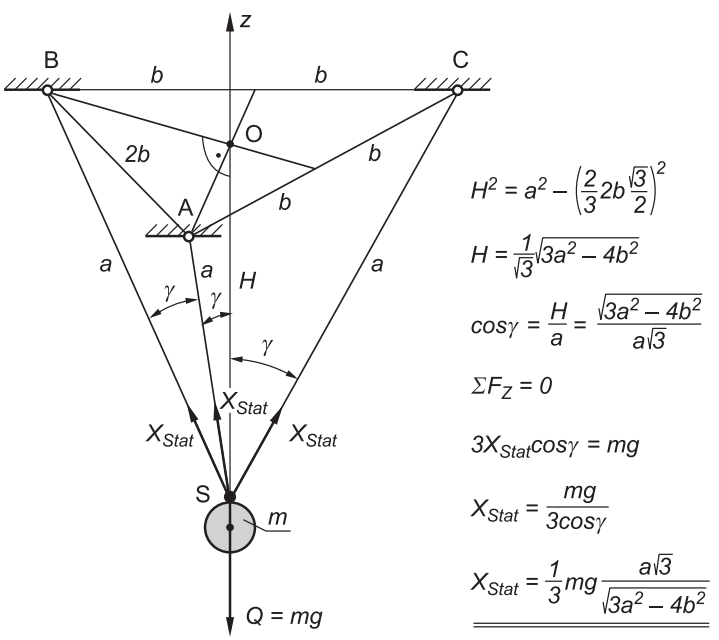

4. Spatial rod structure before cutting the BS cable

According to the designations in Figure 4, in the static case, due to the symmetry of the system relative to the vertical axis passing through point $S$, the forces from static load in three ropes are equal and we can determine them from the equation of equilibrium of the cut node $\mathrm{S}$ :

$$
\begin{aligned}
& \sum F_{z}=0 \rightarrow 3 X_{\text {stat }} \cos \gamma=Q \rightarrow X_{\text {stat }}=\frac{Q}{3 \cos \gamma}=\frac{m g}{3 \cos \gamma}, \\
& H^{2}=a^{2}-\left(\frac{2}{3} 2 b \frac{\sqrt{3}}{2}\right)^{2}=\frac{1}{\sqrt{3}} \sqrt{3 a^{2}-4 b^{2}}, \quad \cos \gamma=\frac{H}{a}=\frac{\sqrt{3}}{3 a} \sqrt{3 a^{2}-4 b^{2}}, \\
& X_{\text {stat }}=\frac{1}{3} m g \frac{a \sqrt{3}}{\sqrt{3 a^{2}-4 b^{2}}} .
\end{aligned}
$$

After a sharp cut in the BS cable, as shown in Figure 5, the distribution of forces at the S node changes. There is still no speed in the system, but there is already an acceleration of a material point with a mass $m$, which we will denote by the letter $p$. The apparent inertia force of d'Alembert $B=m p$ is perpendicular to the height $h$ of the ACS triangle. There are now four 
forces at rope S: two forces $Y_{\mathrm{dyn}}$ on the other two ropes, inertia force $B$, and particle weight $Q=m g$. The sum of projections of force measures on the vertical axis of symmetry leads to the following equation of kinetostatic equilibrium.:

$\sum F_{z}=0 \rightarrow 2 Y_{\mathrm{dyn}} \cos \gamma+m p \cos \left(\frac{\pi}{2}-\beta\right)=m g \quad \rightarrow \quad 2 Y_{\mathrm{dyn}} \cos \gamma+m p \sin \beta=m g$

$\sin \beta=\frac{\frac{1}{3} 2 b \frac{\sqrt{3}}{2}}{h}=\frac{b \sqrt{3}}{3 \sqrt{a^{2}-b^{2}}}, \quad h=\sqrt{3 a^{2}-4 b^{2}}, \quad \cos \gamma=\frac{H}{a}=\frac{\sqrt{3 a^{2}-4 b^{2}}}{a \sqrt{3}}$.

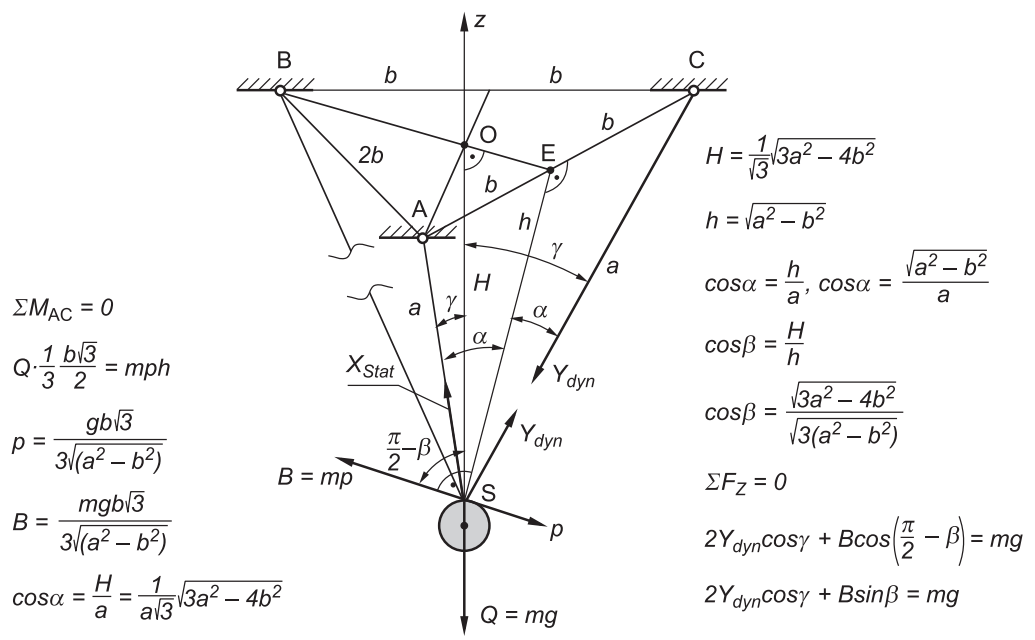

5. Spatial rod structure after cutting the BS cable

The acceleration $p$ missing in formulas (5) and (6) will be determined from the kinetostatic equation of the sum of moments relative to the AC axis perpendicular to the height $h$ and to the inertia force vector $B$. We have therefore:

$\sum M_{\mathrm{AC}}=0 \rightarrow m g \frac{1}{3} 2 b \frac{\sqrt{3}}{2}=m p h \rightarrow p=\frac{b g \sqrt{3}}{3 \sqrt{a^{2}-b^{2}}}$.

Putting now $p, \cos \gamma, \sin \beta$, into the equation of kinetic-equilibrium $(6)_{2}$ we will get one equation with an unknown force $Y_{\mathrm{dyn}}$, occurring in each of the other two links, and therefore:

$2 Y_{\mathrm{dyn}} \frac{\sqrt{3 a^{2}-4 b^{2}}}{a \sqrt{3}}+m \frac{b^{2} g}{3\left(a^{2}-b^{2}\right)}=m g$,

$Y_{\text {dyn }}=m g \frac{a \sqrt{3}}{3 \sqrt{a^{2}-b^{2}}} \frac{3 a^{2}-4 b^{2}}{2\left(a^{2}-b^{2}\right)}$.

The quotient of dynamic force $Y_{\text {dyn }}$ to static force $X_{\text {stat }}$ in the cable is as follows:

$n=\frac{Y_{\mathrm{dyn}}}{X_{\mathrm{stat}}}=\frac{3 a^{2}-4 b^{2}}{2\left(a^{2}-b^{2}\right)}$.

In a special case if $a=2 b$, answer (9) gives $n=\frac{4}{3}$.

\section{Beam suspended on ropes}

Let a horizontal beam $\mathrm{AB}$ of weight $m$ and length $2 l$ hang on two unstretched cables converging at a point $\mathrm{O}$. At one point the $\mathrm{DB}$ cable was suddenly cut. Our task will be to 
determine the components of the beam centre acceleration $a_{x}$ and $a_{y}$, the angular acceleration of the beam $\varepsilon$ and dynamic force $N$ in the second, FA uncut cable, just after the DB cable is cut.. The task formulated in this way is included in the set of tasks by Mieszczerski [4], repeated in the set of Antoniuk and Kiedrzyński [1]. One solution for this task is given in items $[5,7,10]$. Issues related to the dynamics of the discussed systems can also be found in publications $[2,6,8,9]$.

The solution method given in [7] boils down to arranging three equations of kinetostatic equilibrium and two geometric equations on the coordinates of the centre of the beam, which are expressed by two angles of rotation of the cable FA - $\psi$ and the angle of rotation of the beam around the point $\mathrm{A}$ marked as $\varphi$. As a result, after differentiation and elimination of the angle $\psi$ twice, the equation of constraints is obtained, which with the three basic equations of motion leads to the solution of the problem.

Here we will do a little different, more generally, using the properties of the momentary acceleration centre, which at the first moment after breaking the first line coincides with the momentary centre of rotation (speed). In addition, our solution will be valid at any angle value $\varphi \in\left\langle 0, \frac{\pi}{2}\right\rangle$ in which the angle $\varphi$ will be included. According to the markings shown in Figure 6, the three equations of kinetostatic in the adopted coordinate system when entering a variable angle $\varphi$ are written as follows:

$$
\begin{array}{ll}
\sum F_{x}=0 & \rightarrow \quad N \sin \varphi-m a_{x}=0, \\
\sum F_{y}=0 & \rightarrow \quad N \cos \varphi+m a_{y}-m g=0, \\
\sum M_{\mathrm{C}}=0 & \rightarrow \quad N e-J_{\mathrm{C}} \varepsilon=0,
\end{array}
$$

where:

$e=l \cos \varphi, \quad J_{\mathrm{C}}=\frac{1}{3} m l^{2}$.

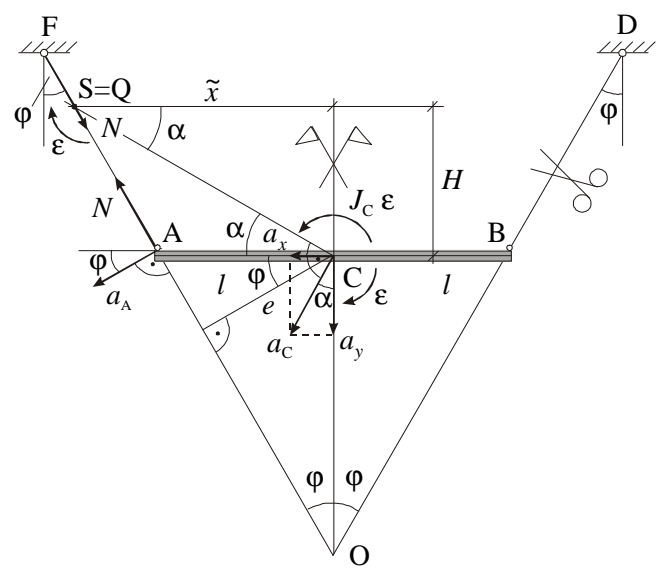

6. Dynamic diagram of the considered rigid beam 


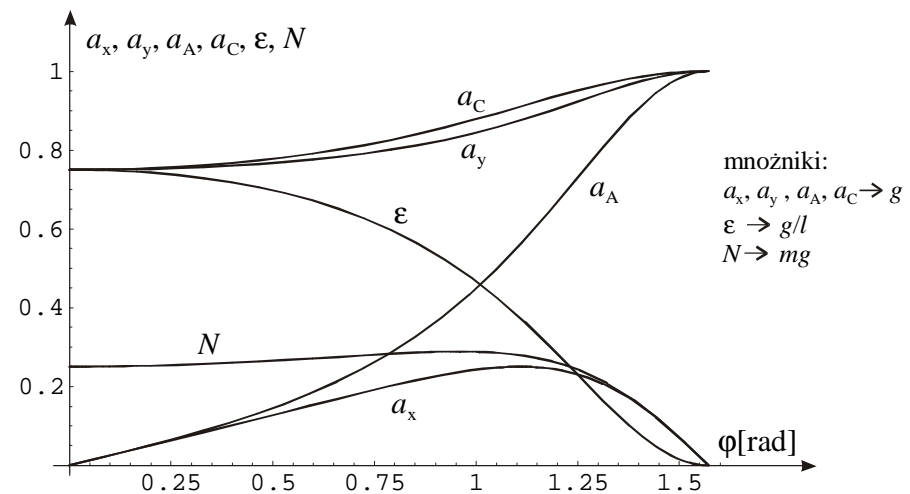

7. Dimensional charts as a function of angle $\varphi$ in a rigid beam

In the first three equations (10) there are four unknowns $a_{x}, a_{y}, \varepsilon$ and $N$. The missing equation of constraints can be determined from the Euler lemma using the properties of the instant acceleration centre $S=Q$, because the moment just after the intersection of the cable DB the instantaneous beam speed and its instantaneous angular velocity are zero. According to the markings in Figure 7 we have:

$$
\begin{aligned}
& \varepsilon \tilde{x}=a_{y}, \quad H=\tilde{x} \operatorname{ctg} \alpha-l \operatorname{ctg} \varphi, \quad H=\tilde{x} \operatorname{tg} \alpha=\tilde{x} \frac{a_{x}}{a_{y}}, \quad \operatorname{tg} \alpha=\frac{a_{x}}{a_{y}}, \\
& H=H \rightarrow \tilde{x}=\frac{a_{y} l \operatorname{ctg} \varphi}{a_{y} \operatorname{ctg} \varphi-a_{x}}, \quad \varepsilon \tilde{x}=a_{y} \rightarrow l \varepsilon \operatorname{ctg} \varphi=a_{y} \operatorname{ctg} \varphi-a_{x} .
\end{aligned}
$$

While solving the system of four equations, which include the kinetostatic equations (10) and the equation of constraints described in the last of the formulas (11), we get the following answers:

$$
\begin{aligned}
& a_{x}=\frac{g \cos \varphi}{4 \cos \varphi \operatorname{ct} g \varphi+\sin \varphi}, \quad a_{y}=\frac{2 g(2+\cos 2 \varphi)}{5+3 \cos 2 \varphi}, \\
& \mathcal{E}=\frac{6 g \cos ^{2} \varphi}{l(5+3 \cos 2 \varphi)}, \quad N=\frac{2 m g \cos \varphi}{5+3 \cos 2 \varphi}, \\
& a_{\mathrm{C}}=\sqrt{\left(a_{x}\right)^{2}+\left(a_{y}\right)^{2}}, \quad a_{\mathrm{A}}=\frac{a_{x}}{\cos \varphi} .
\end{aligned}
$$

Figure 7 shows the graphical answers(12).

In the case $\varphi=\frac{\pi}{6}=30^{\circ}$ answers (12) are reduced to the following:

$a_{x}=\frac{\sqrt{3}}{13} g, \quad a_{y}=\frac{10}{13} g, \quad N=\frac{2 \sqrt{3}}{13} m g, \quad \varepsilon=\frac{9}{13} \frac{g}{l}$.

\section{Circular shiels suspended on ropes}

The last task is a circular rigid shield with a total mass $m$ and radius $R$, also suspended on two unstretched cables, converging at the articulation $\mathrm{O}_{1}$ and forming angles with the vertical axis of symmetry $\varphi$. Let the section A B be equal to $R$. At one point the cable $\mathrm{O}_{1} \mathrm{~B}$ was suddenly cut and the system became a mechanism. According to the designations in Figure $\mathbf{8}$, we are to designate four kinematic and one dynamic quantity $a_{x}, a_{y}, \varepsilon$ and $N$. 


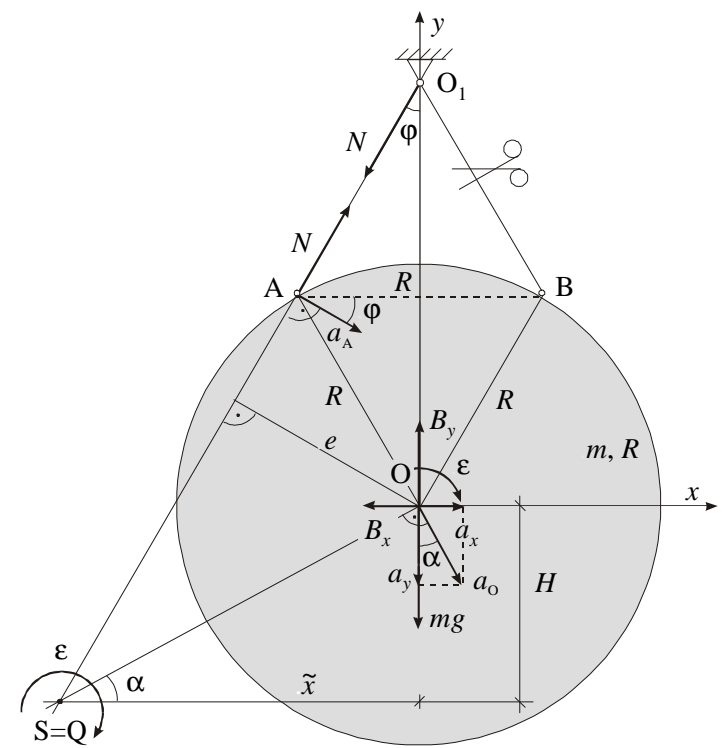

8. Dynamic diagram of a circular shield with the system of accelerations and forces at the moment immediately after cutting the cable $\mathrm{O}_{1} \mathrm{~B}$

We solve the task in the same way as the previous three. We write the three equations of motion of kinetostatic in a standard way:

$$
\begin{array}{ll}
\sum F_{x}=0 & \rightarrow \quad N \sin \varphi-m a_{x}=0, \\
\sum F_{y}=0 & \rightarrow \quad N \cos \varphi+m a_{y}-m g=0, \\
\sum M_{\mathrm{O}}=0 & \rightarrow \quad N e-J_{\mathrm{o}} \varepsilon=0,
\end{array}
$$

where:

$e=\left(\frac{R}{2} \operatorname{ctg} \varphi+R \frac{\sqrt{3}}{2}\right) \sin \varphi=\frac{R}{2}(\cos \varphi+\sqrt{3} \sin \varphi), \quad J_{0}=\frac{1}{2} m R^{2}$.

We determine the missing equation of constraints from the Euler lemma, using the properties of the momentary acceleration centre, which coincides with the momentary centre of rotation just after the intersection of the cable because all speeds at that moment are zero. As shown in Figure 8, we can write the following relationships:

$$
\begin{aligned}
& \varepsilon \tilde{x}=a_{y}, \quad H=\tilde{x} \operatorname{ctg} \varphi-\frac{R}{2}(\operatorname{ctg} \varphi+\sqrt{3}), \quad H=\tilde{x} \operatorname{tg} \alpha=\tilde{x} \frac{a_{x}}{a_{y}}, \quad \operatorname{tg} \alpha=\frac{a_{x}}{a_{y}}, \\
& H=H \rightarrow \tilde{x}=\frac{R(\operatorname{ctg} \varphi+\sqrt{3}) a_{y}}{2\left(a_{y} \operatorname{ctg} \varphi-a_{x}\right)}, \quad \varepsilon \tilde{x}=a_{y} \rightarrow \quad \varepsilon R(\operatorname{ctg} \varphi+\sqrt{3})=2\left(a_{y} \operatorname{ctg} \varphi-a_{x}\right) .
\end{aligned}
$$

When solving the system of four equations: (14) and (15) we get the following answers:

$$
\begin{aligned}
& a_{x}=\frac{2 g \cos \varphi}{\cos \varphi(2 \sqrt{3}+3 \operatorname{ctg} \varphi)+5 \sin \varphi}, \quad a_{y}=g-\frac{2 g \cos ^{2} \varphi}{4-\cos 2 \varphi+\sqrt{3} \sin 2 \varphi}, \\
& \varepsilon=\frac{2 g \cos \varphi(\cos \varphi+\sqrt{3} \sin \varphi)}{a(4-\cos 2 \varphi+\sqrt{3} \sin 2 \varphi)}, \quad S=\frac{2 m g \cos \varphi}{4-\cos 2 \varphi+\sqrt{3} \sin 2 \varphi}, \\
& a_{\mathrm{O}}=\sqrt{\left(a_{x}\right)^{2}+\left(a_{y}\right)^{2}}, \quad a_{\mathrm{A}}=\frac{a_{x}}{\cos \varphi} .
\end{aligned}
$$


In a special case $\varphi=\frac{\pi}{6}=30^{\circ}$ answers (16) are reduced to the following:

$$
a_{x}=\frac{\sqrt{3}}{10} g, \quad a_{y}=\frac{7}{10} g, \quad \varepsilon=\frac{3}{5} \frac{g}{a}, \quad S=\frac{1}{5} \sqrt{3} m g, \quad a_{\mathrm{O}}=\frac{\sqrt{13}}{5} g .
$$

\section{Source materials}

[1] Antoniuk E., Kiedrzyński A. Zadania z mechaniki ogólnej. Dynamika. PWN, Warszawa 1959.

[2] Karelitz G.B., Ormondroyd J., Garrelts J.M. Problems in mechanics. Based on the original collection of I.V. Mestchersky. The MACMILLAN Comp. 1939.

[3] Z. Mazurkiewicz, M. Żórawski, Wpływ nagłej zmiany więzów na odkształcenia ustrojów sprężystych. Archiwum Inżynierii Lądowej 1962, z. 4 s. 439-447; Effect of abrupt change of constraints on deformations of elastic systems. Bull. Acad. Pol. Sci. Ser. Sci. Tech. 1962, Vol.10, No. 9, pp. 395-403.

[4] Mestchersky I.V. Collection of problems in theoretical mechanics. Ed. 36. Nauka, Moskwa 1986 (in Russian).

[5] Neuber H. Lösungen zur Aufgabensammlung Mestchersky. VEB Deutscher Verlag Der Wissenschaften, Berlin 1956.

[6] Rao S.S. Mechanical Vibrations. Pearson Education Inc., New Jersey 2004.

[7] Romicki R. Rozwiązania zadań z mechaniki zbioru W.I. Mieszczerskiego. cz. I-II. PWN, Warszawa 1971.

[8] Smart E. H. Advanced Dynamics. Vol. I-II. MacMillan, London 1951.

[9] Spiegel M.R. Theoretical Mechanics. Schaum's Outline Series. Schaum Publishing CO., New York 1967.

[10] [Szcześniak W. Dynamika analityczna i MATHEMATICA. OW PW, Warszawa 2005.

[11] Szcześniak W. Dynamika teoretyczna w zadaniach dla dociekliwych. OW PW, Warszawa 2010.

[12] Szcześniak W. Dynamika teoretyczna dla zaawansowanych. OW PW, Warszawa 2013.

[13] Szcześniak W., Ataman M. Cztery wybrane zadania z dynamiki analitycznej. Theoretical Foundations of Civil Engineering. Polish-Ukrainian-Lithuanian Transactions 14, OW PW, Warszawa 2006, str. 363-372.

[14] Szcześniak W., Ataman M. Instantaneous change of constraints in mechanics. 10 th International Conference TANSCOMP, Zakopane 2006, pp. 319-328.

[15] Szcześniak W., Ataman M. Sudden change of constraints in selected suspended structures. XXVII R-S-P Seminar, Theoretical Foundation of Civil Engineering, MATEC Web of Conferences 196, 01028 (2018). 